\title{
What Social Work Educators and Practitioners Need to Know on Immigrants' Health Care: a Systematic Review
}

Yuqi Guo ${ }^{1}$, Zhichao Hao ${ }^{2 *}$, David Albright ${ }^{2}$

${ }^{1}$ School of Social Work, University of North Carolina at Charlotte, Charlotte, North Carolina, USA.

${ }^{2}$ School of Social Work, University of Alabama, Tuscaloosa, Alabama, USA.

\author{
Article Details \\ Article Type: Research Article \\ Received date: $21^{\text {st }}$ September, 2019 \\ Accepted date: $22^{\text {nd }}$ October, 2019 \\ Published date: $25^{\text {th }}$ October, 2019
}

"Corresponding Author: Zhichao Hao, School of Social Work, University of Alabama, Tuscaloosa, AL35401, USA. E-mail: zhao6@crimson.ua.edu

Citation: Hao Z (2019) What Social Work Educators and Practitioners Need to Know on Immigrants' Health Care: a Systematic Review. J Pub Health Issue Pract 3: 148. doi: https://doi.org/10.33790/jphip1100148.

Copyright: $\left({ }^{2} 2019\right.$, This is an open-access article distributed under the terms of the Creative Commons Attribution License 4.0, which permits unrestricted use, distribution, and reproduction in any medium, provided the original author and source are credited.

\begin{abstract}
Background: 47 million immigrants are living in the United States and they constitute 14.4 percent of the total population in the United States. As the immigrant population grows rapidly, their health care needs require ongoing and additional attention from social workers and health care practitioners.
\end{abstract}

Methods: This study systematically reviewed content on immigrants and healthcare in social work literature and discussed implications for social services for immigrant populations. Systematic review and content analysis were employed. Research methods, topics, and samples of included studies were screened and coded.

Results: 47 studies met eligibility for inclusion in this review. The majority of included studies were cross-sectional analysis $(60 \%)$, focusing on mental health care issues $(51 \%)$, health care utilization (51\%) and adult immigrant samples (49\%).

Discussion: Encouraging diversity of social work research can directly promote social work services and health care practices for the underrepresented populations. Our findings suggest that more input from the social work profession on evidence-based practice for diverse immigrants are required. Social workers and health care practitioners must continually be reminded of the health care needs of immigrants.

\section{Introduction}

As the immigrant population grows rapidly, health care needs of immigrants require additional attention from social workers. 47 million immigrants are living in the U.S., 14.4 percent of the total population of the United States. The immigrant population has increased significantly in the past decade [1], and immigrants' countries of origin are more diverse than ever before [2]. While many immigrants arrive in the U.S. with good health, their health conditions deteriorate when they stay longer in the U.S. [3]. This might be due in part to the negative consequences of acculturation on health behaviors, such as unhealthy dietary habits [3].

Immigrants experienced inadequate health care due to a myriad of reasons $[1,2,4]$. Compared to U.S.-born individuals, immigrants were less likely to be insured [5,6]. The 1996 Personal Responsibility Work Opportunity Reconciliation Act (PRWORA) resulted in a significant decrease in public health coverage for immigrants; more recently, under the Patient Protection and Affordable Care Act, immigrants who have lived in the U.S. for less than five years are not eligible for J Pub Health Issue Pract Volume 3. 2019. 148
Medicaid [6]. In addition to these structural barriers, cultural barriers exist; limited English proficiency and low levels of acculturation are common barriers for first-generation immigrants when seeking help for health care [7].

Social workers play a critical role in the provision of health care to immigrant populations by attending to social determinants of health (e.g., insurance gaps, social and family support, health literacy) and by addressing social and behavioral problems that affect health status and social functioning [8]. The National Association of Social Workers' (NASW) Code of Ethics [9] mandates that social workers in public health and primary care work to reduce race, ethnic, and gender-based health care disparities and ensure the health right for all. According to a national study conducted by the Center for Workforce, $52 \%$ of licensed social workers practice in health care settings, and approximately half of the social work jobs were in health care and social assistance settings [10]. To tackle health care disparities, it is necessary for social workers to address structural and cultural barriers through advocating for health care use, improving acculturation, and promoting social support among immigrant communities. Therefore, it is important for social work educators and practitioners to understand the health care needs of immigrant populations. The purpose of our study was to review the research studies conducted on immigrants and their health care, focusing on published scientific social work journals in the United States and discuss the implications to social work practice and research. We sought to answer this research question: What has been published in U.S.-based social work journals about immigrants' health care?

\section{Methods}

Adherence to the PRISMA guideline, we systematically reviewed social work literature, and an analytical approach to address our research question. Content analysis is a systematic approach used to identify and analyze content in the literature which relates to a specific topic. Summative content analysis (SCA) is an effective method that analyzes specific content in particular journals and attempts to explore the usage of certain content [11]. SCA starts with identifying and counting the frequency of specific content in text data with specific research purposes and then interprets the content [12].

As for the present study, four steps were taken to search and analyze the content of physical health care issues, mental health care issues, and health care utilization among immigrants. They included: 1) social work journal selection, 2) article searching, 3) article JPHIP, an open access journal ISSN- 2581-7264 
screening and 4) content coding. Details of each step were discussed below. The findings were analyzed in a summative manner to provide an overview of relevant content to social service practitioners and educators. Since this study was a systematic review of the literature, an institutional review board review was not required.

\section{Journal Selection}

The journals of social work used for this review were determined by the journal impact factor (JIF) from the Journal Citation Report (2019) [13]. JIF is widely regarded as a quality ranking for journals [14], and published social work journals with JIFs have a large audience and extensive articles related to social work research, education and practice. For our review, journals were included if they focused primarily on social work, were located in the U.S., and were published in English-language journals. Based on these criteria, 16 journals were included in this review: Social Work in Public Health, Social Work in Health Care, Social Work, Health \& Social Work, AFFILIA: Journal of Women and Social Work, Journal of Social Service Research, Social Work Research, Social Service Review, Research on Social Work Practice, Journal of Social Work Education, Children and Youth Services Review, Clinical Social Work Journal, Journal of Family Social Work, Family Relations, Qualitative Social Work, and Journal of the society for social work and research.

\section{Article Searching}

We used the following key terms: "health care" OR "mental health" OR "physical health" OR "behavioral health" OR "health care utilization" AND "immigra*". Up to August 2019, the initial search yielded 10,048 articles from these 16 selected social work journals.

\section{Article Screening}

One hundred and thirty articles were identified, and after duplicate articles were removed, 97 articles were left. These articles were further screened to meet the following criteria: (a) written in the English language; (b) sampled immigrant populations in the United
States; and (c) focused on health care issues within the U.S. health care system. Two investigators independently reviewed abstracts of the 97 articles and, when needed, the full texts. Any disagreement on the inclusion decision of an article was resolved through discussion in consensus meetings, and a full consensus for the final list of articles was reached.

\section{Content Coding}

In this study, content referred to the text of selected studies, including results and discussion. Coding and themes were developed systematically. According to the research question, three categorical domains were developed: study samples, health issues, and research method. Initial codes were identified based on these three domains to categorize each article's immigrant populations, health issues, and methodology. Two investigators independently read and applied the coding structure to the identified articles. Any discrepancy between the investigators was discussed until consensus was reached. The initial rate of agreement between coders was $90 \%$; after discussions, $100 \%$ agreement was reached.

\section{Results}

A final set of studies $(n=47)$ were analyzed to identify content related to immigrants' health care. An outline of the study selection process was provided in Figure 1. The 47 articles included in the final analysis were categorized by each article's study samples (Table 1), health issues (Table 2), and research methods (Table 3). As for age sampling, about half $(n=23,49 \%)$ of the 47 studies sampled immigrant adults (aged 18 to 54), while the rest of studies sampled immigrants aged 55 or older $(n=13,28 \%)$ and children and youth $(n=12,26 \%)$ immigrants. By race and ethnicity, the majority of the articles focused on Latin American immigrants $(n=21,45 \%)$ or Asian $(n=19,40 \%)$, while 3 studies focused on African immigrants and 1 focused on Middle Eastern immigrants. Among these studies, the study conducted by [15] focused on both Latin American and Asian immigrants.

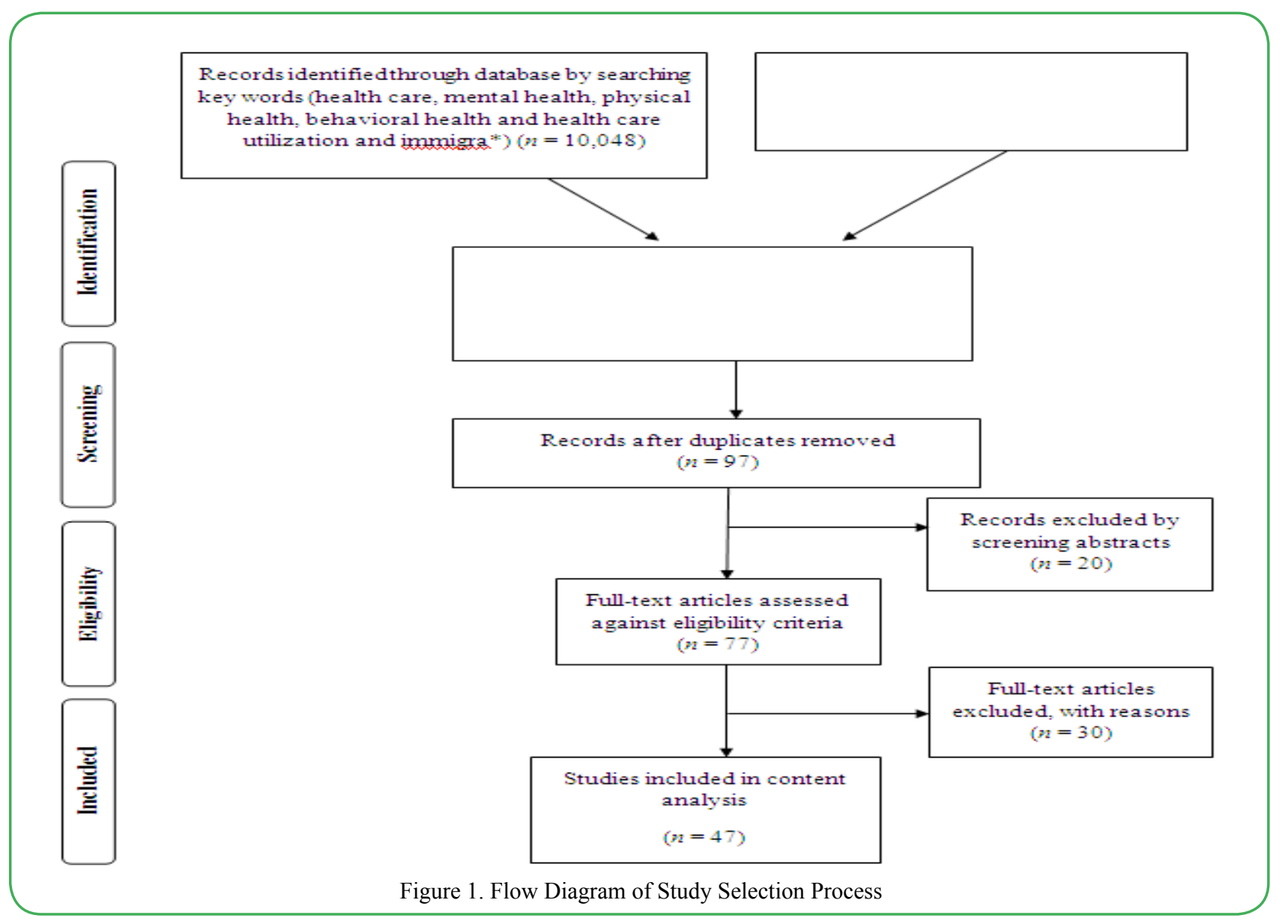

J Pub Health Issue Pract

Volume 3. 2019. 147 


\begin{tabular}{|c|c|c|c|}
\hline Population & Number & Percentage & Study \\
\hline Middle East Immigrants & 1 & $2 \%$ & (Martin, 2009) \\
\hline African immigrants & 3 & $6 \%$ & (Chaumba, 2011; Kamya, 1997; Yorke, Voisin, \& Baptiste, 2016) \\
\hline Latin American immigrants & 21 & $45 \%$ & $\begin{array}{l}\text { (Aranda, 2008; Becerra et al., 2015; Calvo, 2014; Cardoso, 2018; Benuto, } \\
\text { Casas, Gonzalez, \& Newlands, 2018; Cardoso et al., 2014; Finno-Velasquez } \\
\text { et al., 2016; Huang et al., 2011; Li, 2014; Lightfoot, Thatcher, Thomas, } \\
\text { Coyne-beasley, \& Chapman, 2019; Lovato, Lopez, Karimli, \& Abrams, } \\
\text { 2018; Marsiglia et al., 2011a; Murguía et al., 2003; Pandey \& Kagotho, } \\
\text { 2010; Piedra \& Byoun, 2012; Rahill et al., 2011; Ruiz et al., 2013; Schapiro, } \\
\text { Gutierrez, Blackshaw, \& Chen, 2018; Wheeler \& Mahoney, 2008; Yeo \& } \\
\text { Johnson, 2013; Zambrana et al., 1994; ) }\end{array}$ \\
\hline Asian immigrants & 19 & $40 \%$ & $\begin{array}{l}\text { (Bhattacharya, 2004; Chang \& Moon, 2016; Collier et al., 2012; Gellis, } \\
\text { 2003; Huang et al., 2011; Jang et al., 2011; Kwong \& Mak, 2009; Lai, 2009; } \\
\text { Lee, 2010; Lee \& Hwang, 2014; Koh, 2018; Leung et al., 2012; Mao et al., } \\
\text { 2015; Mui, 1996; Mui et al., 2007b;Nguyen, 2008; Lee \& Jang, 2016; Woo } \\
\text { et al., 2014; Yeo \& Johnson, 2013) }\end{array}$ \\
\hline Child \& Youth immigrants & 12 & $26 \%$ & $\begin{array}{l}\text { ( Benuto, Casas, Gonzalez, \& Newlands, 2018; Cardoso, 2018; Cardoso } \\
\text { et al., 2014; Finno-Velasquez et al., 2016; Johnson, Padilla, \& Votruba- } \\
\text { Drzal, 2017; Li, 2014; Lightfoot, Thatcher, Thomas, Coyne-beasley, \& } \\
\text { Chapman, 2019; Nguyen, 2008; Lovato, Lopez, Karimli, \& Abrams, 2018; } \\
\text { Schapiro, Gutierrez, Blackshaw, \& Chen, 2018; Ybarra, Ha, \& Chang, } \\
\text { 2017; Zambrana et al., 1994) }\end{array}$ \\
\hline Older immigrants & 13 & $28 \%$ & $\begin{array}{l}\text { (Aranda, 2008; Chang \& Moon, 2016; Jang et al., 2011; Lai, 2009; Lee, } \\
\text { 2010; Lee \& Hwang, 2014; Mao et al., 2015; Martin, 2009; Mui, 1996; Mui } \\
\text { et al., 2007b; Nguyen \& Reardon, 2013; Woo et al., 2014; Yeo \& Johnson, } \\
\text { 2013) }\end{array}$ \\
\hline Adult immigrants & 23 & $49 \%$ & $\begin{array}{l}\text { (Becerra et al., 2015; Bhattacharya, 2004; Calvo, 2014; Chaumba, 2011; } \\
\text { Collier et al., 2012; Gellis, 2003; Huang et al., 2011; Kamya, 1997; Koh, } \\
\text { 2018; Kwong \& Mak, 2009; Leung et al., 2012; Maleku \& Aguirre, 2014; } \\
\text { Marsiglia et al., 2011; Murguía et al., 2003; Pandey \& Kagotho, 2010; Piedra } \\
\text { \& Byoun, 2012; Rahill et al., 2011; Ruiz et al., 2013; Lee \& Jang, 2016; Toft } \\
\text { et al., 2013; Wheeler \& Mahoney, 2008; Yorke, Voisin, \& Baptiste, 2016; } \\
\text { Zambrana et al., 1994) }\end{array}$ \\
\hline
\end{tabular}

Note: Some studies focus on more than one population.

Table 1 Summary of Review Articles $(n=47)$ by Focus Population

\begin{tabular}{|c|c|c|c|}
\hline Topic & Number & Percentage & Study \\
\hline physical health and care issues & 8 & $17 \%$ & $\begin{array}{l}\text { (Bhattacharya, 2004; Chaumba, 2011; Lightfoot, Thatcher, Thomas, } \\
\text { Coyne-beasley, \& Chapman, 2019; Lee \& Hwang, 2014; Mao et al., 2015; } \\
\text { Murguía et al., 2003; Nguyen \& Reardon, 2013; Schapiro, Gutierrez, } \\
\text { Blackshaw, \& Chen, 2018) }\end{array}$ \\
\hline Mental health and care issues & 24 & $51 \%$ & $\begin{array}{l}\text { (Aranda, 2008; Benuto, Casas, Gonzalez, \& Newlands, 2018; Cardoso } \\
\text { et al., 2014; Cardoso, 2018; Chang \& Moon, 2016; Chaumba, 2011; } \\
\text { Collier et al., 2012; Finno-Velasquez et al., 2016; Gellis, 2003; Jang et } \\
\text { al., 2011; Kamya, 1997; Koh, 2018; Lai, 2009; Lee \& Hwang, 2014; Li, } \\
\text { 2014; Marsiglia et al., 2011; Lovato, Lopez, Karimli, \& Abrams, 2018; } \\
\text { Mui, 1996; Nguyen, 2008; Nguyen \& Reardon, 2013; Piedra \& Byoun, } \\
\text { 2012; Schapiro, Gutierrez, Blackshaw, \& Chen, 2018; Woo et al., 2014; } \\
\text { Zambrana et al., 1994) }\end{array}$ \\
\hline Health care utilization & 24 & $51 \%$ & $\begin{array}{l}\text { (Becerra et al., 2015; Benuto, Casas, Gonzalez, \& Newlands, 2018; Calvo, } \\
\text { 2014; Chaumba, 2011; Huang et al., 2011; Johnson, Padilla, \& Votruba- } \\
\text { Drzal, 2017; Koh, 2018; Kwong \& Mak, 2009; Lee, 2010; Leung et al., } \\
\text { 2012; Maleku \& Aguirre, 2014; Martin, 2009; Mui et al., 2007; Nguyen } \\
\text { \& Reardon, 2013; Pandey \& Kagotho, 2010; Rahill et al., 2011; Ruiz } \\
\text { et al., 2013; Lee \& Jang, 2016; Toft et al., 2013; Wheeler \& Mahoney, } \\
\text { 2008; Ybarra, Ha, \& Chang, 2017; Yeo \& Johnson, 2013; Yorke, Voisin, } \\
\text { \& Baptiste, 2016; Zambrana et al., 1994) }\end{array}$ \\
\hline 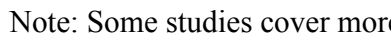 & Hail one & lth topics. & \\
\hline
\end{tabular}




\begin{tabular}{|l|l|l|l|}
\hline \multicolumn{1}{|c|}{ Method } & Number & Percentage & \multicolumn{1}{c|}{ Study } \\
\hline RCT & 0 & $0 \%$ & None \\
\hline Non-RCT & 1 & $2 \%$ & ( Piedra \& Byoun, 2012;) \\
\hline Mixed-method & 2 & $4 \%$ & ( Cardoso, 2018; Ruiz et al., 2013) \\
\hline Cohort study & 2 & $4 \%$ & (Marsiglia et al., 2011; Toft et al., 2013) \\
\hline Conceptual study & 2 & $4 \%$ & (Bhattacharya, 2004; Wheeler \& Mahoney, 2008) \\
\hline Literature review & 3 & $6 \%$ & $\begin{array}{l}\text { (Lovato, Lopez, Karimli, \& Abrams, 2018; Maleku \& Aguirre, 2014; } \\
\text { Mao et al., 2015) }\end{array}$ \\
\hline Qualitative study & 9 & $19 \%$ & $\begin{array}{l}\text { (Benuto, Casas, Gonzalez, \& Newlands, 2018; Collier et al., 2012; } \\
\text { Lightfoot, Thatcher, Thomas, Coyne-beasley, \& Chapman, 2019; } \\
\text { Kwong \& Mak, 2009; Lee, 2010; Martin, 2009; Murguía et al., 2003; } \\
\text { Rahill et al., 2011; Schapiro, Gutierrez, Blackshaw, \& Chen, 2018) }\end{array}$ \\
\hline Cross-sectional & 28 & $60 \%$ & $\begin{array}{l}\text { (Aranda, 2008; Becerra et al., 2015; Calvo, 2015; Cardoso et al., } \\
\text { 2014; Chang \& Moon, 2016; Chaumba, 2011; Finno-Velasquez et al., } \\
\text { 2016; Gellis, 2003; Huang et al., 2011; Jang et al., 2011; Johnson, } \\
\text { Padilla, \& Votruba-Drzal, 2017; Kamya, 1997; Koh, 2018; Lai, 2009; } \\
\text { Lee \& Hwang, 2014; Leung et al., 2012; Li, 2014; Mui, 1996; Mui } \\
\text { et al., 2007; Nguyen, 2008; Nguyen \& Reardon, 2013; Pandey \& } \\
\text { Kagotho, 2010; Lee \& Jang, 2016; Woo et al., 2014; Ybarra, Ha, \& } \\
\text { Chang, 2017; Yeo \& Johnson, 2013; Yorke, Voisin, \& Baptiste, 2016; } \\
\text { Zambrana et al., 1994) }\end{array}$ \\
\hline
\end{tabular}

Table 3 Summary of Review Articles $(n=47)$ by Research Method

By health issues, half $(\mathrm{n}=24,51 \%)$ of the articles presented results on mental health issues. $24(51 \%)$ articles addressed health care utilization by immigrants, followed by 8 articles on the topic of physical health care. Also, among these studies, some studies cover more than one topic. For example, studies conducted by $[7,8]$ paid attention to all three health topics. Besides, studies conducted by $[16,17]$ focused on physical health care and mental health issues. In addition, studies conducted by [18-20] focused on mental health issues and health care utilization. A variety of research methodological approaches were employed. The majority $(\mathrm{n}=28,60 \%)$ were crosssectional analyses, followed by 9 qualitative studies, 3 literature reviews, 2 cohort studies, 2 conceptual studies, 2 mixed-method study and 1 non-randomized controlled trial (RCT).

\section{Discussion}

The present study reviewed previous studies on immigrants' health care published in social work journals in the United States and comprehensively answered the research question about immigrants/ their health care needs. Findings of the review provided important insights for social work profession on the immigrant and their health care. Research methods, health topics, and target populations of the reviewed studies, as well as implications of social work practice and research were discussed in the following.

\section{Research Methods of Reviewed Studies}

More than half of the social work articles on immigrants' health care used quantitative methods and relied heavily on cross-sectional analyses. 28 studies used cross-sectional, secondary data analysis to examine the correlation between demographic factors, such as level of acculturation, socioeconomic status, education, and healthcare outcomes. The cross-sectional analysis used in the observational study primarily described odds ratios [21]. In health research, crosssectional analysis was a useful tool to assess health care utilization, health behavior, and health conditions in the populations of interest. However, the cross-sectional study design was less sensitive to the systematic bias than RCT design, which was currently considered the best method to avoid such bias by selecting and allocating samples randomly to control vs. comparative groups [22]. Only one study used a non-RCT design to test the effect of cognitive-behavioral group therapy intervention on reducing depression among Latino immigrants [23]. Although RCT designs were underutilized in the social work articles methodologically, when inferring causality, RCT designs were not preferred over non-RCT designs.

Of the included studies, $19 \%(\mathrm{n}=9)$ were included in this review used qualitative methods. These nine qualitative studies $[17,18,24-$ 30] used individual interviews or focus groups as the primary data collection methods to explore immigrants' experiences with health care. Qualitative methods are more appropriate in understanding subjective meanings of a phenomenon, providing in depth information that quantitative methods often fail to capture. Qualitative studies can be very useful to social work health research as they are centered on an individual's experience and respect diverse backgrounds, which is consistent with a core social work value, respect for "dignity and worth of the person" [31].

\section{Target Populations of Reviewed Studies}

Children in immigrant families were underrepresented in social work research. Of all children in the U.S., 25.8 percent were children who have at least one immigrant parent $(22.5 \%)$ or were immigrants themselves (3.3\%) (U.S. Department of Health and Human Services, $2015)$. In this review, the majority of studies $(n=36 ; 77 \%)$ focused on adults and older immigrant, while only $26 \%$ of studies $(n=12)$ were about children in immigrant families. Among these studies, 5 studies [17,18,27,32,33] focused on the children immigrants themselves, and the rest $(\mathrm{n}=7)$ focused on children in immigrant families. A growing concern considering that the number of children in immigrant families grew quickly, and they became more ethnically diverse [34].

Also, children in immigrant families were at a disadvantage in many aspects of health care [35]. For example, immigrant children were more likely than those from U.S. citizen families to lack health insurance coverage [36], and to significantly underutilize health care services $[37,38]$. Prior studies also showed that children from immigrant families were at a greater risk for developing psychosocial problems (e.g., substance abuse, depression, low self-efficacy, and violent behaviors) $[39,40]$ due to the gaps between their immigrant parents' level of acculturation [41] and their parents' limited knowledge of health care resources $[42,43]$. However, in light of the currently available literature, there was a significant lack of academic 
literature on health care among children in immigrant families.

\section{Health Topics of Reviewed Studies}

According to the findings of the present study, mental health, health care utilization, and physical health were the most prominent findings on immigrants and their health care. These three health care topics attracted academic attention and plural of studies have been done in immigrants and their health care. In this review, care issues related to mental health $(\mathrm{n}=24 ; 51 \%)$ and health care utilization (n $=24 ; 51 \%$ ) were the most popular topic among reviewed studies, followed by and physical health care $(n=8 ; 17 \%)$. The results of this current review suggested that helpful information exists to inform social workers about immigrants' health care. However, some health issues were understudied in social work professions, such as selfmanagement of chronic illnesses, well-known disease epidemics, sexual and reproductive health including teen pregnancy, cancers with high incidence rates, and mental health care of LGBTQ among immigrant populations [21,44-46].

In addition, since many immigrants experience barriers in accessing health care, such as low acculturation, lack of knowledge, and lack of resources and information, a gradual approach to improving their access should include educational programs [47] and outreach efforts [48]. Such efforts can include partnerships between social work professionals and immigrant communities, involving service providers, faith organizations, and community leaders $[49,50]$.

\section{Implications for Practice}

The importance of providing health care services to immigrants in a culturally appropriate manner has repeatedly been emphasized in prior research [10,16,24,28,47,51]. Practitioners should be keenly aware of the cultural differences in conceptualization and the expression of health problems to provide culturally sensitive service [24,51-53]. Some immigrants might prefer alternative treatments (e.g., folk healers, herbal medicine, and acupuncture) or prefer to seek help from providers from their native countries who are more in line with their cultural beliefs [8]. Understanding patients' cultural backgrounds could facilitate better communications and interactions between health care practitioners and immigrant patients, potentially improving immigrants' health care satisfaction in the U.S. [10,54].

Health care practitioners also play a critical role as cultural brokers. One useful tip for practitioners is to allow enough time for immigrants to describe their symptoms and to build a trusted relationship [28]. Furthermore, a huge need exists for bilingual healthcare workers or translation services since many immigrants have limited English proficiency $[20,32,33,51,53]$. It would be helpful if health care practitioners could be trained with bilingual capability [50]. Supportive relationships have been identified as a source of resilience for individuals' health conditions [55]. Prior research suggests that social work professionals work to strengthen immigrants' social support systems [10,16,49,55-59], especially for single female immigrants $[20,23]$ and older Asian immigrants $[16,59,60]$. Since many immigrants have a strong family-centered culture of care $[61,62]$, it is recommended that health care practitioners work both with immigrant patients and their family members [52].

In addition to families, the community is another major source of social support for immigrants. Therefore, social work professionals should attend to those experiencing weak ties to their communities $[20,58]$. The recent health care bill dispute put immigrant populations in a more vulnerable position, especially for undocumented immigrants [44]. Undocumented immigrants are historically excluded from almost all governmental social services and many public services. Therefore, health care practitioners face significant difficulties in advocating for health care services for undocumented immigrants or low income documented immigrants who are not yet eligible for governmental social services (e.g., immigrants who stay in the U.S. less than five years) $[63,64]$

J Pub Health Issue Pract

Volume 3. 2019. 148
To bridge this critical gap of immigrants' health care services, many non-profit organizations and programs might provide health care services for immigrants across the nation, but only a specific fraction of needs for immigrants who are excluded from governmental social services $[63,65]$. Therefore, it is the critical time for health care practitioners to take all possible actions for policy advocacy, which should include strongly urging all stakeholders to revisit and repeal the bans on public health care programs for undocumented immigrants and certain legal immigrants and their families [48].

\section{Implication to Social Work Research}

According to the results of the content analysis, we proposed four suggestions for social work research development. First, social work research should apply more randomized controlled study design to generate new findings and infer causality, which can be useful for best evidence healthcare practice. Also, social work journals should provide more opportunities for qualitative researchers to publish studies on immigrants' health care to inform culture-competent health care services. Third, studies on sub-groups of vulnerable populations and their health are needed to promote evidence-based practice and education in the field of social work. Since the social work discipline pays close attention to marginalized, vulnerable groups regardless of their population size, concerning that little information exists in the most-often cited journals of the social work profession on those other than Asian and Latin American immigrants. Finally, encouraging academic diversity can be one way to increase the capacity for social work research, practice, and education on health care issues of diverse immigrant groups.

\section{Limitation}

The present study systematically reviewed research articles published in the most-often cited U.S.-based social work journals focusing on immigrants' health care. Selecting social work journals by impact factors from journal citation reports might have caused the omission of other journals with articles on the immigrants' health care. However, our review does not aim to explain the reasons for the current lack of such content in social work journals. More research efforts and dissemination of research findings by our profession through social work journals can help relatively remedy the lack of studies on immigrants' health care needs.

It was beyond the scope of our review to include non-U.S. based social work journals; thus, results must be interpreted with caution, especially when the findings are generalized to immigrants' health care in other countries. In addition, the search terms used for this study are limited. Some specific terms of health issues were not applied, such as reproductive health, which may have excluded some potential studies on immigrants' health care. Further studies could consider focusing on reviewing specific health issues, such as teen pregnancy and sexual health among LGBTQ populations among immigrants.

\section{Conclusion}

The present study reviewed prior studies on immigrants' health care which were published in the peer-reviewed journals in the United States. In light of research findings suggested that further social work studies make more efforts to investigate marginalized immigrant populations' health care and some understudied health issues, particularly social work researchers may consider to conducting more randomized controlled studies on immigrant populations' health care. For instance, social work researchers might pay closer attention to the health of children in immigrant families and immigrant teens' reproductive health.

The current social work literature provided some promising implications of practice in our review. Social workers may promote social justice by advocating policy changes to provide a supportive, culturally and linguistically appropriate health care environment for immigrants [66]. Health care advocacy should aim to eliminate JPHIP, an open access journal ISSN- 2581-7264 
discriminatory practices based on various factors, such as the immigrant's race or ethnicity, immigration status or lack of English proficiency. Coupled with the growing anti-immigrant sentiment across the U.S., immigrant populations are under threats of discrimination in many social settings, including health care settings.

Social workers should be further encouraged to condemn discriminatory practices against immigrant populations and continue to advocate for their rights in physical and mental well-being. In addition, further efforts should be made to promote social justice in health care, which include but are not limited to providing affordable health care to low-income immigrants, improving health insurance coverage rate among immigrants, and expanding the proportion of receiving health care services and developing tailored services in child welfare systems for children in immigrant families $[8,24,52,66]$.

Findings provide future direction in the development of social work education, research and professional practice regarding immigrants' health care. Social workers must continually be reminded of the health care needs of immigrants. An ongoing focus on this topic in the primary journals of social work can help keep practitioners and educators updated in their efforts to promote immigrants' health care.

\section{Acknowledgment}

This study did not have financial support and did not study any human participants or animals. The authors are grateful to Lynn Tobola, the social work librarian from the School of Social Work, University of Alabama, for her help with the literature search for this manuscript.

Conflict of interest: The authors declare no conflict of interest.

\section{References}

1. Jacquez F, Vaughn L, Zhen-Duan J, Graham C (2016) Health care use and barriers to care among Latino immigrants in a new migration area. J Health Care for the Poor and Underserved 27: 1761-1778.

2. Sarría-Santamera A, Hijas-Gómez AI, Carmona R, GimenoFeliú LA (2016) A systematic review of the use of health services by immigrants and native populations. Pub Health Reviews. Bio Med Central.

3. Hyman I, Dussault G (2000) Negative consequences of acculturation on health behaviour, social support and Stress among Pregnant Sourheast Asian Immigrants Women in Montreal: An Exploratory Study.

4. Pulver A, Ramraj C, Ray JG, O'Campo P, Urquia ML et al. (2016) A scoping review of female disadvantage in health care use among very young children of immigrant families. Soc Sci Med 152: 50-60.

5. Derose KP, Escarce JJ, Lurie N (2007) Immigrants and health care: Sources of vulnerability. Health Affairs.

6. Kandula NR, Grogan CM, Rathouz PJ, Lauderdale DS (2004) The unintended impact of welfare reform on the medicaid enrollment of eligible immigrants. Health Services Res 39: 1509-1526.

7. Nguyen D, Reardon LJ (2013) The Role of Race and English Proficiency on the Health of Older Immigrants. Soc Work in Health Care 52: 599-617.

8. Chaumba J (2011) Health Status, Use of Health Care Resources, and Treatment Strategies of Ethiopian and Nigerian Immigrants in the United States. Soc Work in Health Care 50: 466-481.

9. Ethical Standards in Social Work: Preface. (n.d.).

10. Huang B, Appel H, Ai AL (2011) The effects of discrimination and acculturation to service seeking satisfaction for Latina and Asian American women: implications for mental health professions. Soc Work in Public Health 26: 46-59.

11. Hsieh H, Shannon S (2005) Three approaches to qualitative content analysis. Qualitative Health Res 15: 1277-1288.

J Pub Health Issue Pract

Volume 3. 2019. 148
12. Krippendorff K (1989) Content analysis. Int Enc Commun 1: 403-407.

13. Chukhrova N, Johannssen A (2019) J Citation Report 2019: Impact Factors 2018.

14. Wilkinson RG (1992) Education and Debate For Debate. BMJ Open, 304(April) 165-168.

15. Yeo YA, Johnson MM (2013) Healthy Immigrant Effect on Older Adult Immigrants in Relation to Welfare Reform. J Soc Soc Work Res 4: 182-197.

16. Lee KH, Hwang MJ (2014) Private Religious Practice, Spiritual Coping, Social Support, and Health Status among Older Korean Adult Immigrants. Soc Work Pub Health 29: 428-443.

17. Schapiro NA, Gutierrez JR, Blackshaw A, Chen JL (2018) Addressing the health and mental health needs of unaccompanied immigrant youth through an innovative school-based health center model: Successes and challenges. Children and Youth Services Rev 92: 133-142.

18. Benuto LT, Casas JB, Gonzalez FR, Newlands RT (2018) Being an undocumented child immigrant. Children and Youth Services Rev 89: 198-204.

19. Koh E (2018) Prevalence and Predictors of Depression and Anxiety among Korean Americans. Soc Work Public Health 33: 55-69.

20. Zambrana RE, Ell K, Dorrington C, Wachsman L, Hodge D (1994) The relationship between psychosocial status of immigrant Latino mothers and use of emergency pediatric services. Health Soc Work 19: 93-102.

21. Jong EC (2005) United States epidemiology of hepatitis A: influenced by immigrants visiting friends and relatives in Mexico? Am J Med 118: 50S-57S.

22. Warriner D (2008) How to Read a Paper: The Basics of Evidence-Based Med BMJ 336: 1381.2-1381.

23. Piedra LM, Byoun SJ (2012) Vida Alegre: Preliminary Findings of a Depression Intervention for Immigrant Latino Mothers. Rese Soc Work Pract 22: 138-150.

24. Collier AF, Munger M, Moua YK (2012) Hmong Mental Health Needs Assessment: A Community-Based Partnership in a Small Mid-Western Community. Am J Community Psychol 49: 73-86.

25. Kwong K, Mak A (2009) Health care and cancer screening experience of chinese immigrants in New York City: a qualitative study. Soc Work in Health Care 48: 321-347.

26. Lee JS (2010) Channels of health communications used among Korean and Asian Indian older adults. Soc Work Health Care 49: $165-175$.

27. Lightfoot AF, Thatcher K, Simán FM, Eng E, Merino Y et al. (2019) "What I wish my doctor knew about my life": Using photovoice with immigrant Latino adolescents to explore barriers to healthcare. Qualitative Soc Work 18: 60-80.

28. Martin SS (2009) Illness of the mind or illness of the spirit? Mental health-related conceptualization and practices of older Iranian immigrants. Health Soc Work 34: 117-126.

29. Murguía A, Peterson RA, Zea MC (2003) Use and implications of ethnomedical health care approaches among Central American immigrants, Health Soc Work 28: 43-51.

30. Rahill GJ, Dawkins MP, De La Rosa M (2011) Haitian picuristes/ injectionists as alternatives to conventional health care providers in South Florida. Soc Work Pub Health 26: 577-593.

31. Cousins L (2014) Code of Ethics of the National Association of Social Workers. In Encyclopedia of Human Services and Diversity. Taylor \& Francis Group.

JPHIP, an open access journal ISSN- 2581-7264 
32. Cardoso JB (2018) Running to stand still: Trauma symptoms, coping strategies, and substance use behaviors in unaccompanied migrant youth. Children and Youth Services Rev 92: 143-152.

33. Johnson AD, Padilla CM, Votruba-Drzal E (2017) Predictors of public early care and education use among children of lowincome immigrants. Children and Youth Services Rev 73: 24-36.

34. Huang ZJ, Yu SM, Ledsky R (2006) Health status and health service access and use among children in U.S. immigrant families. Am J Pub Health.

35. Zhou M (1997) Growing Up American: The Challenge Confronting Immigrant Children and Children of Immigrants. Annual Rev Sociol 23: 63-95.

36. Committee on the Health and Adjustment of Immigrant Children and Families (1999) Children of Immigrants: Healt, Adjustment, and Public Assistance. National Academies Press (US).

37. Guendelman S, Schauffler HH, Pearl M (2001) Unfriendly shores: How immigrant children fare in the U.S. health system. Health Affairs 20: 257-266.

38. Kataoka SH, Stein BD, Jaycox LH, Wong M, Escudero P et al. (2003) A school-based mental health program for traumatized latino immigrant children. J Am Acad Child Adolescent Psychia 42: 311-318.

39. Reijneveld SA, Harland P, Brugman E, Verhulst FC, VerlooveVanhorick SP et al. (2005) Psychosocial problems among immigrant and non-immigrant children: Ethnicity plays a role in their occurrence and identification. Eur Child Adolescent Psychia 14: 145-152.

40. Singh GK, Yu SM, Siahpush M, Kogan MD (2008) High levels of physical inactivity and sedentary behaviors among US immigrant children and adolescents. Archives Pediatrics Adolescent Med 162: 756-763.

41. Lim SL, Yeh M, Liang J, Lau AS, McCabe K et al. (2009). Acculturation gap, intergenerational conflict, parenting style, and youth distress in immigrant chinese american families. Marriage and Family Rev 45: 84-106.

42. Yu SM, Huang ZJ, Schwalberg RH, Kogan MD (2005) Parental awareness of health and community resources among immigrant families. Maternal and Child Health J 9: 27-34.

43. Yu SM, Nyman RM, Kogan MD, Huang ZJ, Schwalberg RH (2004) Parent's language of interview and access to care for children with special health care needs. Ambulatory Pediatrics, 4: 181-187.

44. Hahm HC, Lee J, Chiao C, Valentine A, Lê Cook B et al. (2016) Use of Mental Health Care and Unmet Needs for Health Care Among Lesbian and Bisexual Chinese-, Korean-, and Vietnamese-American Women. Psychiatric Services 67: 1380 1383 .

45. Logie CH, Lacombe-Duncan A, Lee-Foon N, Ryan S, Ramsay H (2016) "It's for us -newcomers, LGBTQ persons, and HIVpositive persons. You feel free to be": A qualitative study exploring social support group participation among African and Caribbean lesbian, gay, bisexual and transgender newcomers and refugees in Toronto, BMC Int Health and Human Rights 16: 18 .

46. McMahon BJ (2005) Epidemiology and natural history of hepatitis B. Seminars in Liver Disease.

47. Ruiz E, Aguirre RTP, Mitschke DB (2013) What Leads NonU.S.-Born Latinos to Access Mental Health Care? Soc Work Health Care 52: 1-19.

48. Pandey S, Kagotho N (2010) Health insurance disparities among immigrants: are some legal immigrants more vulnerable than others? Health Soc Work 35: 267-279.
49. Aranda MP (2008) Relationship between religious involvement and psychological well-being: A social justice perspective. Health Soc Work 33: 9-21.

50. Mui AC, Kang SY, Kang D, Domanski MD (2007) English language proficiency and health-related quality of life among Chinese and Korean immigrant elders. Health Soc Work, 32: 119-127.

51. Woo H, Lee KH, Hong YJ (2014) Age differences in stressors, coping resources, and general well-being among Korean immigrants. J Soc Service Res 40: 415-428.

52. Li Y (2014) Intergenerational conflict, attitudinal familism, and depressive symptoms among Asian and Hispanic adolescents in immigrant families: A latent variable interaction analysis. J Soc Service Res 40: 80-96.

53. Maleku A, Aguirre RTP (2014) Culturally competent health care from the immigrant lens: a qualitative interpretive metasynthesis (QIMS). Soc Work Pub Health 29: 561-580.

54. Wheeler DP, Mahoney AM (2008) Caribbean immigrants in the United States--health and health care: the need for a social agenda. Health Soc Work 33: 238-240.

55. Marsiglia FF, Kulis S, Perez HG, Bermudez-parsai M et al. (2011) Hopelessness, Family Stress, and Depression among Mexican-Heritage Mothers in the Southwest 7-18.

56. Becerra D, Androff D, Messing JT, Castillo J, Cimino A et al. (2015) Linguistic Acculturation and Perceptions of Quality, Access, and Discrimination in Health Care Among Latinos in the United States. Soc Work Health Care 54: 134-157.

57. Cardoso JB, Dettlaff AJ, Finno-Velasquez M, Scott J, Faulkner $M$ (2014) Nativity and immigration status among Latino families involved in the child welfare system: Characteristics, risk, and maltreatment. Children and Youth Services Rev 44: 189-200.

58. Gellis ZD (2003) Kin and Nonkin Social Supports in a Community Sample of Vietnamese Immigrants. Social Work.

59. Lai DWL (2009) Older chinese' attitudes toward aging and the relationship to mental health: an international comparison. Soc Work Health Care 48: 243-259.

60. Chang M, Moon A (2016) Correlates and Predictors of Psychological Distress Among Older Asian Immigrants in California. J Gerontological Soc Work 59: 77-97.

61. Flores G (2006) Language barriers to health care in the United States. New Eng J Med. Massachusetts Medical Society.

62. Uttal L (2006) Organizational cultural competency: Shifting programs for Latino immigrants from a client-centered to a community-based orientation. Am J Community Psychol 38: 251-262.

63. Edward J (2014) Undocumented Immigrants and Access to Health Care: Making a Case for Policy Reform. Policy, Politics, Nurs Pract 15: 5-14.

64. Nandi A, Galea S, Lopez G, Nandi V, Strongarone S et al. (2008) Access to and use of health services among undocumented Mexican immigrants in a US urban area. Am J Pub Health 98: 2011-2020.

65. Mao W, Wu B, Chi I (2015) Oral Health among Older Chinese Immigrants and Implications for Social Work Practice: Figure 1: Health Soc Work 40: e75-e82.

66. Calvo R (2015). Health Literacy and Quality of Care among Latino Immigrants in the United States. Health Soc Work 41: e44-e51. 